\title{
Semantic Web Design of RFID Pharmaceutical Drugs Analytics and Clinics Tracking System
}

\author{
Murizah Kassim, Ismail Din, Roslina Mohamad, Norsuzila Ya'acob \\ Faculty of Electrical Engineering, Universiti Teknologi MARA, 40450 UiTM Shah Alam, Selangor, MALAYSIA. \\ email: murizah@uitm.edu.my, ORCID: 0000-0002-8494-4783
}

\begin{abstract}
This paper presents a development of a Pharmaceutical Drugs and Clinics Tracking system which uses Radio Frequency Identification technology. RFID technology has grown actively in the past few years and is nowadays sought to be implemented for the identification of products and for traceability in the medical and health sector. Most people faced difficulties to find the specific type of pharmaceutical drugs that needed at their location which the pharmaceutical drugs are less identified. This research has designed system that present pharmaceutical drugs information, quantity inventory and the shortlisted clinics according to customer's demand. The system also provided to track the correct information related to the drugs detail. The method involved development use of hardware, software and programming code of RFID reader which automatically scan the arrived medicines of RFID tags. Query data such as drugs ID and names is kept in database in computer and cloud that send by the controller. Drugs data are accessed by users through online system which includes location of the available clinics based on user demand. Result presents data analytics using Fusionex cloud that listed the drugs details with clinic's location. API Geolocation is designed with the calculated route to users in this system. Four clinics have been taken as model in running the model which analyzed available drugs inventory as presented online on Fusionex GIANT platform. Statistic on updated quantity and availability of drugs product are listed based on user's search. The analytic graph presented predicted affected area based on purchased value of medicine. This system is significant for medical and health sector demonstrate how RFID technology helps in better monitoring and trace drugs product which helps users to find the clinic's location automatically identified of needed drugs nearby.
\end{abstract}

Key words: Semantic Web, RFID, Pharmaceutical Drugs, Tracking system, Clinics System, Data analytics

\section{INTRODUCTION}

Radio Frequency Identification (RFID) is one of the major technologies in the field of identification. Its technology is based on a wireless communication, particularly through radio frequency waves, between a tag attached to an object and an interrogator[1]. It is a technology that allows storing and retrieving a huge amount of data through electromagnetic transmission using radio frequency (RF) devices and a strategically installed technological structure. Today's more systems are developed using RFID technology which this system is more convenient for product identification. The RFID technology has been widely used in various fields, including the health care sector [2] in smart pharmacy monitoring [3], pharmacy supply chain [4], accounting system in health care [5], Enhancing Pharmaceutical Packaging through a Technology Ecosystem [6], RFID tag-based dashboard is introduced that contain the necessary details about the products to be manufactured for production line improvement. [7] which all reviews are to quickly identify remote objects. Research identified that yet, current recognized of RFID based system are not appropriate for some Medical Devices management at hospital[8]. This reason has made the pressing need to improve safety and traceability in public health care environment. RFID technology is dominant for the automation and optimization of supply-chain activities. Some are designed for implementation of cost-effective RFID. Thus, RFID tags can significantly improve the efficiency of inventory management, especially in the pharmacy supply chain. A reviews described that drugs tracking can be enhanced in the pharmaceutical manufacturing plants all across the world paving the way for the wide deployment of the Internet of Things (IoT) [9]. This paper has discussed a context-aware middleware for RFID based pharmacy supply chain to offer a deeper intelligence for the objects monitoring. The current system is not systematic as they must arrange and classes the type of pharmaceutical drugs manually.

Most people faced difficulties to find the specific type of pharmaceutical drugs that needed at their location which the pharmaceutical drugs less identified. Users commonly need to come to the clinics or pharmacies first to identify whether the pharmaceutical drugs are available or not at that pharmacies or clinics. Smart mobile or web-based pharmacy has become a necessary requirement in improving the quality of healthy life in the last five years. Many semantic webs are designed related to improve pharmacy management in the areas. A web-based tool built from pharmacy claims data to assess adherence to respiratory medications in primary care has been developed [10]. It is aimed to explore the barriers and facilitators of assessing medication adherence in clinical practice and to develop a novel web-based tool that allowed physicians to monitor adherence using pharmacy claims data. Many more semantic web are designed to helps improved the pharmacies 
management like Drug-drug interaction discovery and a semantic web platform for drug abuse [11] and e-commerce $[12,13]$.

Due to the growing of RFID research and development, this research is looking at the reliability promising areas for pharmacies in Selangor, Malaysia. This research has aimed to ease community to find their specific information of the product using RFID and localization maps systems[14]. This research presents a development of a RFID with database, tracking or GPS system and monitoring system. User can access information of the medicine including their exact location and their availability through webpage and mobile application. The systems calculate and provide the route to users based on availability of the searching drugs. This system is successfully designed, developed, and tested on small circuit board with update the database on the server and stored the data in cloud.

\section{LITERATURE REVIEW}

\subsection{RFID}

RFID systems are made up of several components such as a RFID antenna used for communication, a chip for unique identification of an electronic product code and for data storage, a reader or interrogator for wave emission and reception upon backscattering from the RFID tag, and a host computer for data saving and analysis[15]. Figure 1 shows the RFID antenna, used for electromagnetic wave capture and emission, is made up of a metal pattern, which imposes the emission frequency and the chip is capable for a maximum energy transmission. Fig. 2 shows the electronic product code information services (EPCIS), which control information contained by EPC, which is the tag ID, date of manufacture, country of origin, production batch and shipment as in Figure2.

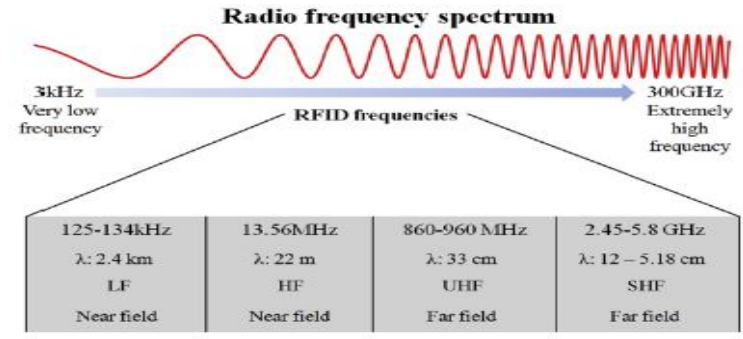

Figure 1. Radio Frequency spectrum of RFID

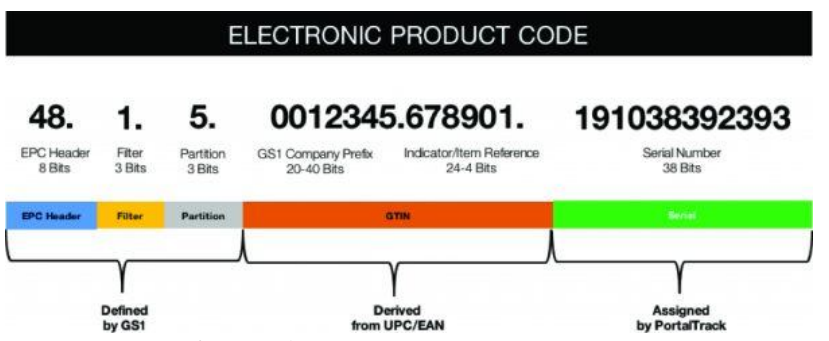

Figure 2: electronic product code

\subsection{Semantic Web Design}

Semantic Web is a development of the World Wide Web in which data in web pages is structured and tagged in such a way that it can be read directly by computers. Many semantic webs are designed to learn data web automatically which Artificial
Intelligence is used to predict future results. A Semantic web health care and life sciences (HCLS) interest group has been developed and online. The mission of the Semantic Web Health Care and Life Sciences Interest Group (HCLS IG) was to develop, advocate and support the use of Semantic Web technologies across health care, life sciences, clinical research and translational medicine[16]. The Semantic Web technologies domain as they depend on the interoperability of information from many disciplines. The design of web is important where it is reliable, real time and updated database with secured data transmission[17, 18].

\subsection{Pharmaceutical Drugs Analytics and Clinics}

Recently, with new technologies advancement, a tremendous amount of data has been gathered which including clinical data. This clinical data is to gain insights and knowledge useful for clinical decisions, drug recommendations, and better diagnoses, among many other uses. A research on the enormous impacts of big data on medical stakeholders, patients, physicians, pharmaceutical and medical operators, and healthcare insurers has been reviewed to find the different challenges to get the best benefits from all this big data and the available applications [19]. Latest found that many pharmaceutical drugs analytics and clinics has been done and were presented as models, analytics platform, virtual reality concept[20], AI methods and much more[21].

\section{METHODOLOGY}

\subsection{Architecture Diagram and Flowchart}

This system is divided into 3 stages which are first is that all pharmaceutical drugs tags are scanned for their specific detail via RFID system. Figure 3 shows the architecture diagram which first the reader sent the information details to the database. At the second stage, all data in the database were compared by the raspberry pi controller and arrange them into the specific type. Next, the controller derived the data analysis on the database send information including the place to the cloud system. The database is transparent to users through the design website on pharmaceutical drugs details, availability status and the location of clinics or pharmacist as follow the users demand.

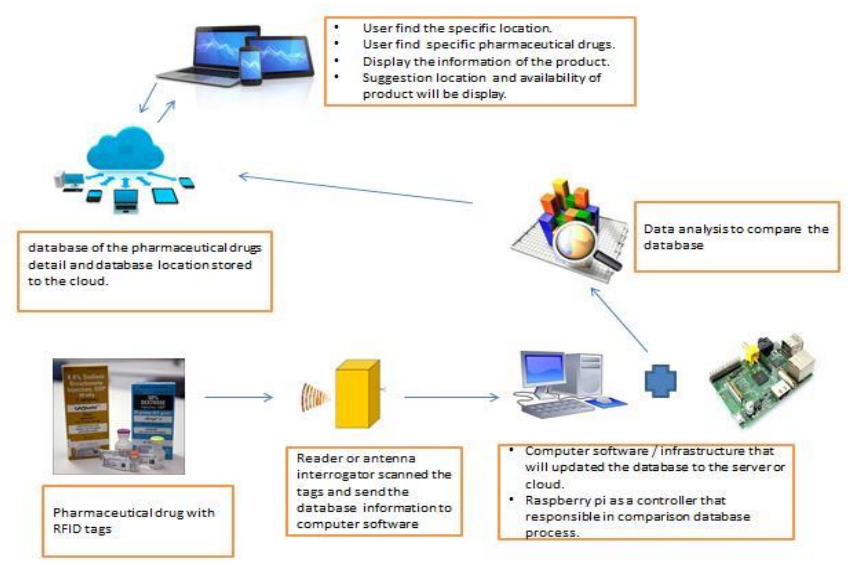

Figure 3: Architecture of the system. 
Figure 4 shows the flowchart of the designed system. The RFID tag has scanned by the reader and all data of the tags are stored in database. Python program run the data analysis on the database and compared and arranged them into their specific type. Data are updated to the cloud and can be accessed through the website. Python program has analyzed the data on the updated database and display the finding on the product information. Another script of python is run that calculated the route to the location to user. Every change in database will be updated to the system.

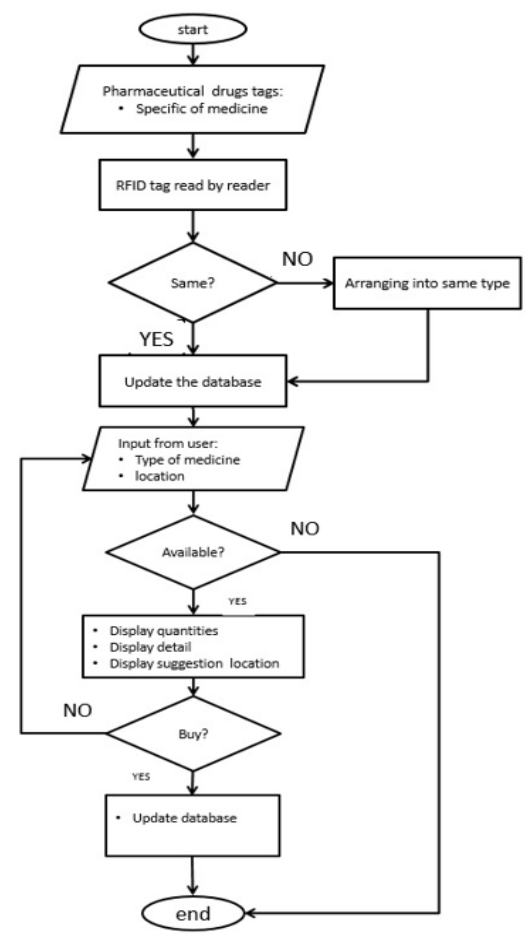

Figure 4: Flowchart of the System

\subsection{Data Retrieval Technique}

Figure 5 shows how data retrieval technique gathered from tags to presentable analytics. Clinics and pharmacies are locked with their API Geolocation and database through the cloud.

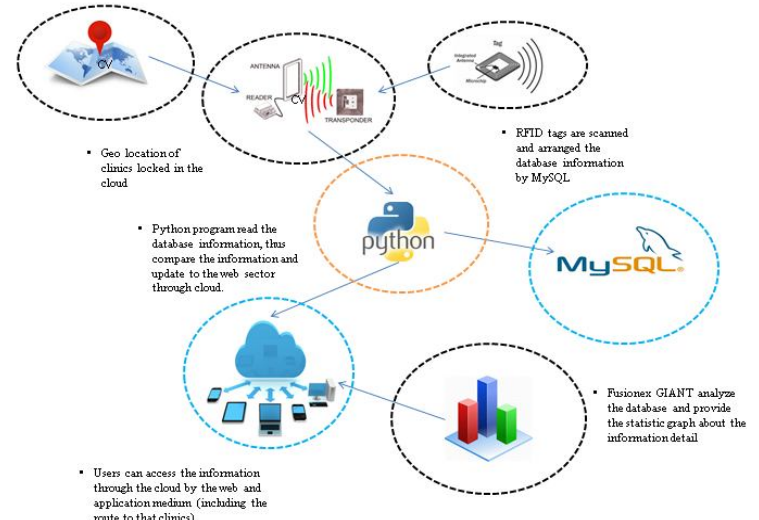

Figure 5: Data Retrieval Technique

When the pharmaceutical drugs arrive on the certain clinic or pharmacies, all the medicine information tags are scanned then the data is arranged in the MySQL program. The counter program is used to increase or decrease the quantity of the same specific type of medicine. The python program will compared the database detail either it is increasing or decreasing in the MySQL and arrange them with their specific types, thus stored through the cloud Google or Fusionex cloud including the location of that clinic and also calculate the route to users by API Geolocation. Fusionex GIANT will analyse the data to provide the statistical analytic graph on the detail information such as updated quantity and availability of the product. The analytic data also was used to predict the affected area based on purchased medicine on the clinics or pharmacies. Web and application sector will access the cloud and provide suggestion the nearest route to users.

\subsection{Schematic Diagram}

Figure 6 show the schematic diagram of this system that shows reader MFRC522 is connected to the respective I/O ports on the Raspberry Pi 3.

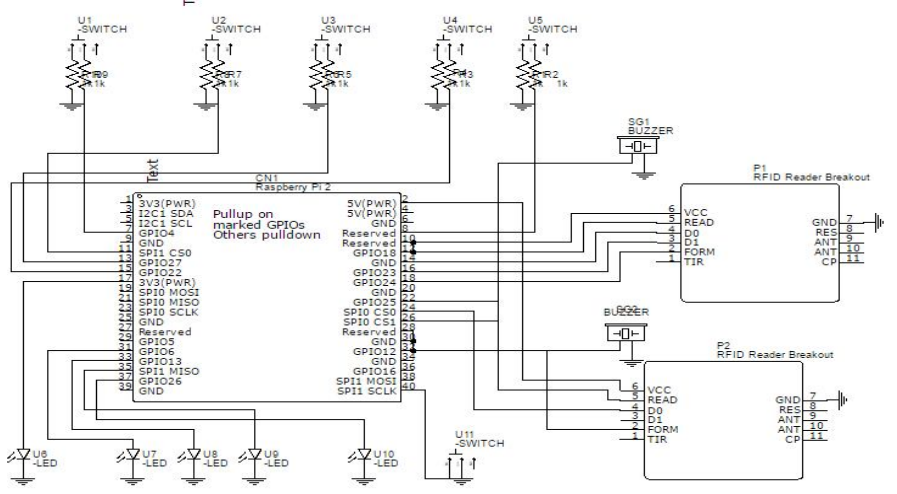

Figure 6: The schematic diagram of this system

Several modification and addition of parameters are made such as connection with database MySQL and PHP by using python program. The switch is used to represent the four different clinics. Two reader of MFRC522 represent the in and out data. If reader A scan the tags the data are stored into the system while if reader B scan the tags the data is clear from the sytem and all the data recorded will display in the form of analytic graph that can be use for prediction of affected area based on purchased medicine.

\subsection{System Testing}

Figure 7 shows the system is successfully designed, developed, and tested on small circuit board with update the database on the server and stored the data in cloud.

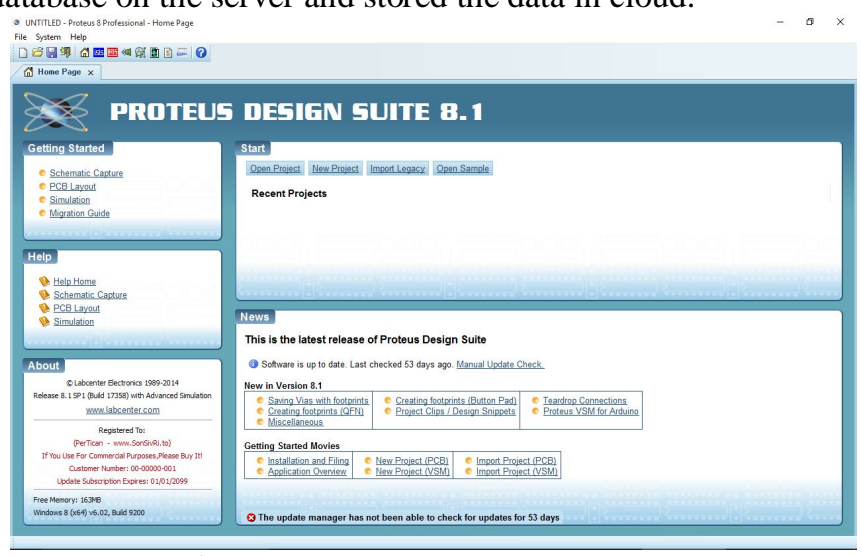

Figure 7: Testing with Proteus Software 
Proteus software package for computer assisted design, simulation and design of electronic circuits is used for tested. It consists of two main parts which are circuit design environment (ISIS) and the simulator with VSM and the ARES the circuit board designer. The software is easily simulated the circuit first for testing and the best circuit that can run and suitable with my project.

\section{RESULT AND DISCUSSION}

Results show the successful of the developed semantic web design of RFID pharmaceutical drugs analytics and clinics tracking system on Windows and application when it is launched.

\subsection{Data Collection}

Figure 8 shows data was inserted to MySQL database then updated to the cloud server. The sector represents each clinic. The tags are read by the reader, then the unique ID details of each tag was inserted into database and sent to the cloud by the server.

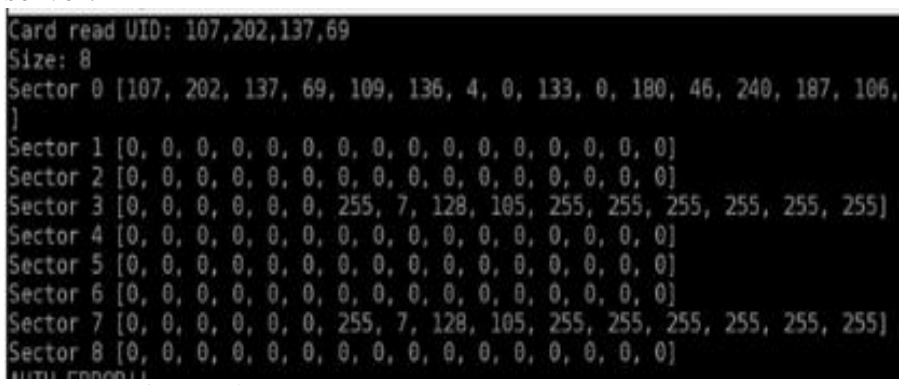

Figure 8: Data of unique ID details of each tag

\subsection{MySQL Database}

There are four type database table that has been created to successful running data into SQL database. The created database tables are Clinic table, registration table, In and Out Store Table and Type of medicine table. Figure 9 shows sample of In and Out Store Table Database which presents list of clinics that has been locked with their API location and place ID. The registration table is used to register unique ID of the tag so that it can be used by the system. In and out store table record the transaction of in and out of the medicine that has been registered in the system. The type of medicine table is used to store overall quantity available of medicine on market according their specific type.

\subsection{Semantic Web}

A Semantic web page has been designed where users are able to read the information, news, features, and article about the statistical disease as shows in Figure 10. The list of clinics and their address location are kept online, and the current news are available on the about page. Figure 11 presents the medical information page gave users authentication to check the availability of the medicine in the market. More information on medicine details and location of medicine are available on track and trace page. These data are updated frequently on quantity of medicine available are in real time.

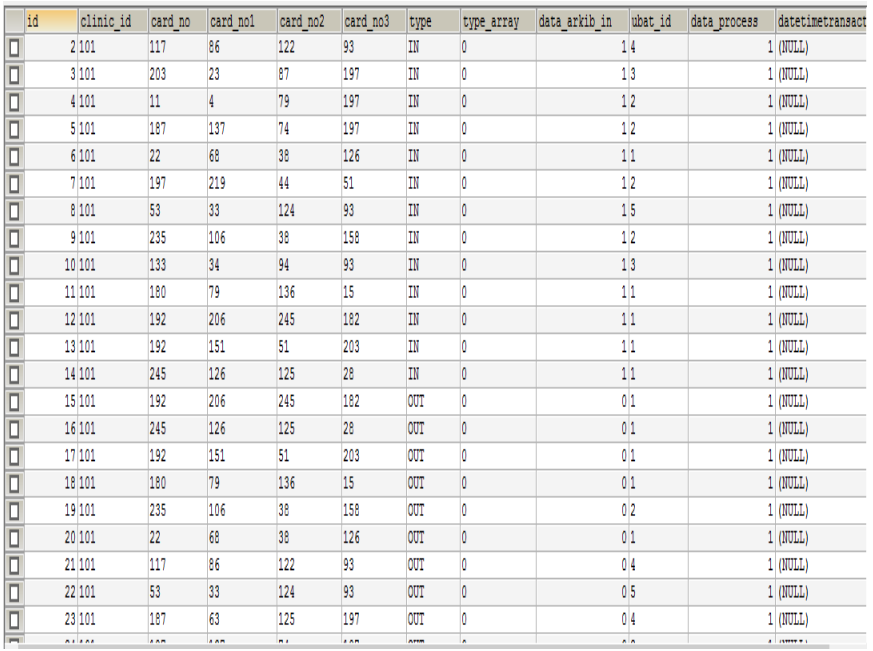

Figure 9: In and Out Store Table Database

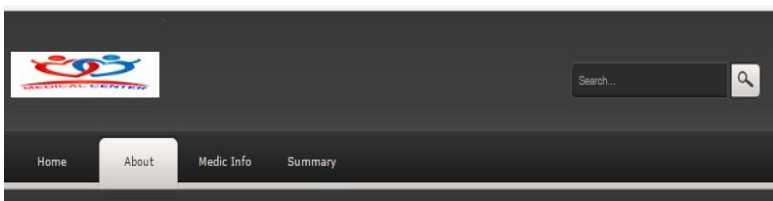

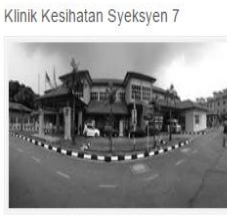

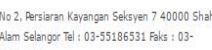
Alam Sedangor

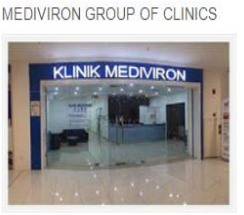

MEDDRRON GROUP OF CLIMICS is one of the laggest

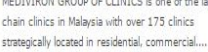

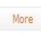

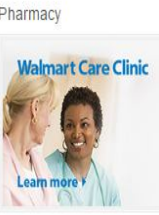

When you make Walmart yaur pharmacy, you gat more than just low prices. We offer quick, converient on pour mobile deicice...
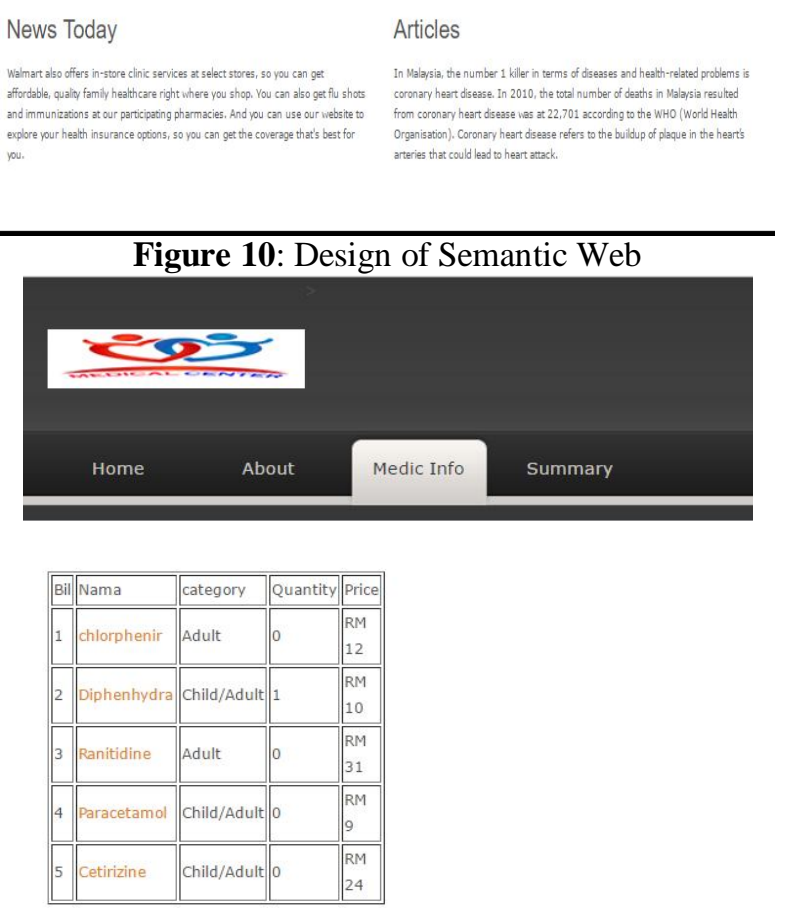

Figure 11: Medical Information page 
Figure 12 shows In track and trace page User can read the details information and instruction to consume that medicine. The precaution steps also been stated in this page.

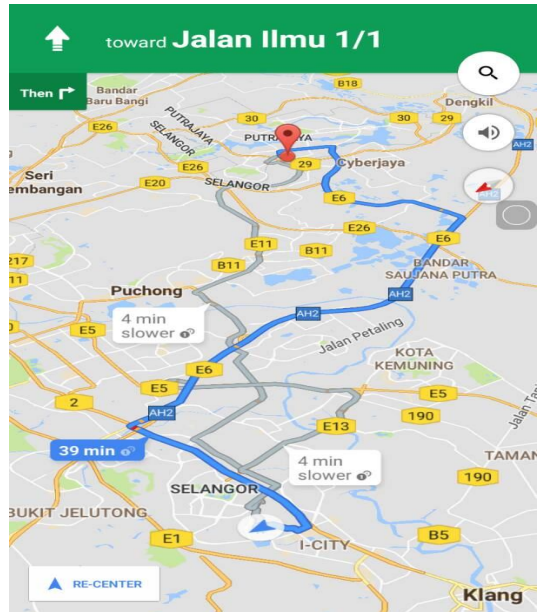

Figure 12: Track and Trace Page on Location of Clinic

The availability of that medicine also been displayed this page. If user want to know the exact location of the medicine, they just need to click on the "go" button at the bottom of the page. The location of the medicine will be displayed to user on google maps. User can route to the clinic by using waze or maps. It shows the suggested location on google maps and the route to that location.

\subsection{Data Analytics on WEB}

Figure 13 shows the graph of the amount of purchased medicine in each clinic and were analyze by the Fusionex GIANT. Figure 14 to Figure 18 present the analytics drug for the four of the clinics sample. The bar chart represents total purchased medicine of all clinics. The line chart represents the total medicine purchased by clinic. There are many types of medicine also recorded and analyzed in the system. Thus, a conclusion can be made that which area has the serious health condition. Based on the statistic users are aware of the health condition in that area.
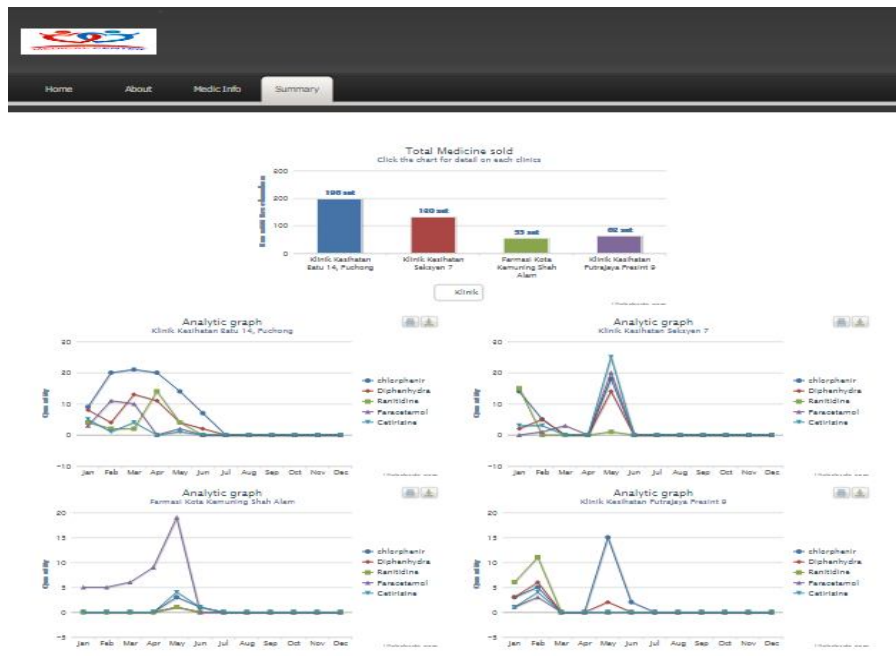

Figure 13: Data analytics graph

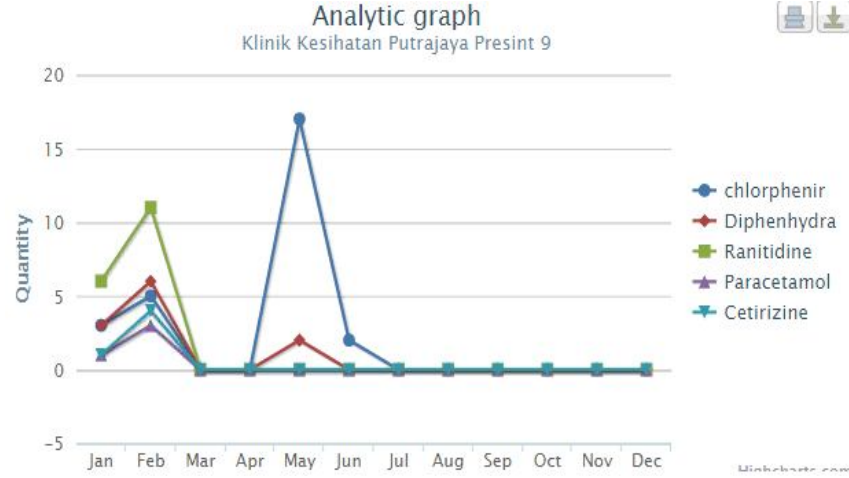

Figure 14: Analytics on Clinic 1

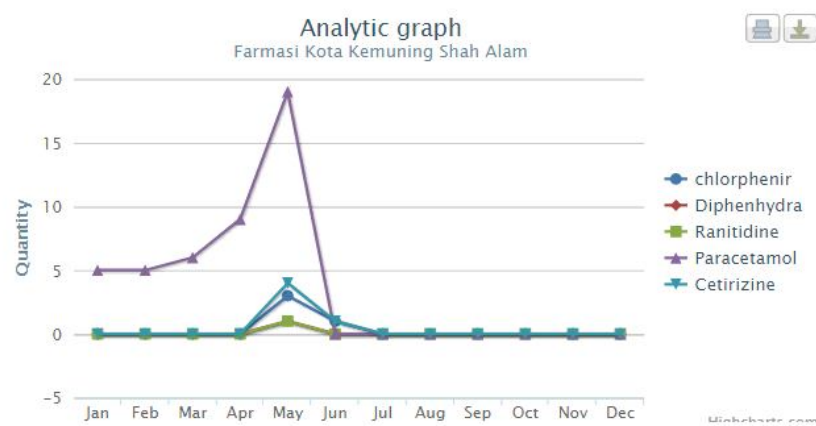

Figure 15: Analytics on Clinic 2

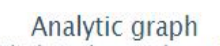

Klinik Kesihatan Seksyen 7

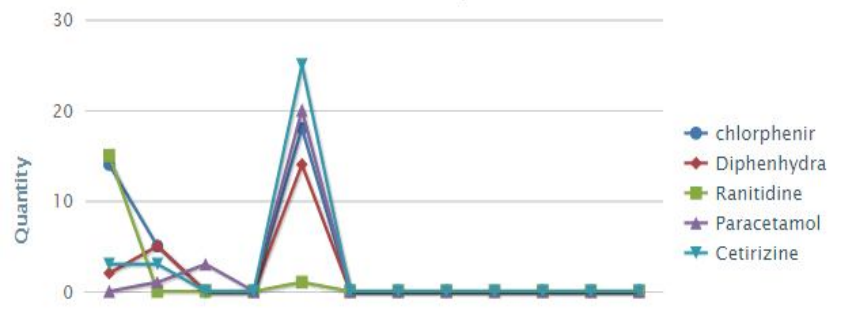

-10 Jan Feb Mar Apr May Jun Jul Aug Sep Oct Nov Dec

Figure 16: Analytics on Clinic 3

Analytic graph

Klinik Kesihatan Batu 14, Puchong

30

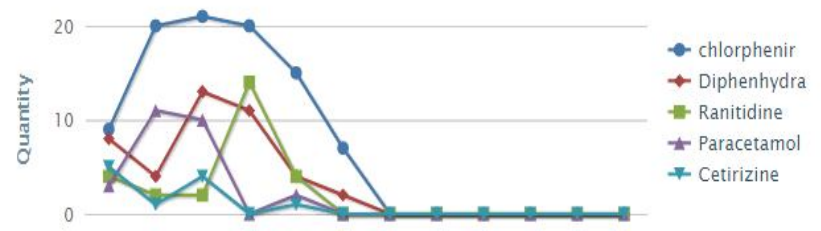

-10 Jan Feb Mar Apr May Jun Jul Aug Sep Oct Nov Dec

Figure 17: Analytics on Clinic 4 


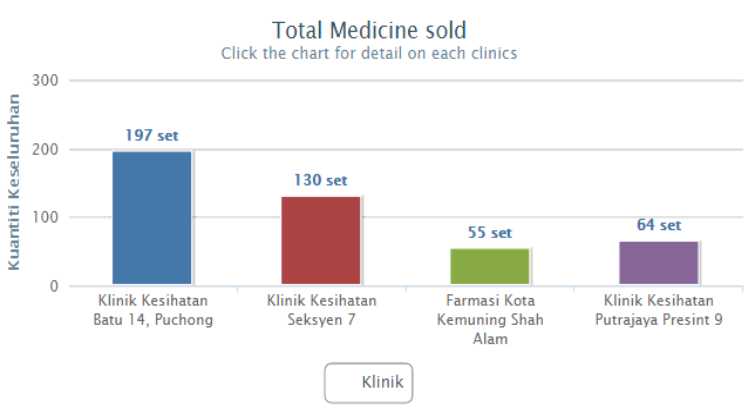

Figure 18: Analytics on Total Medicine Sold

\section{CONCLUSION}

RFID Pharmaceutical Drugs and Clinics Tracking System are smart systems that ease users to find the specific medicine or pharmaceutical drugs. This system has been successfully designed with semantic web of tracking drugs and clinics that allowed user to classify the pharmaceutical drugs according to their specific types automatically by using RFID system. This system also enable user to identify the required information data of the pharmaceutical drugs through the websites and application. Most people are commonly needed to come to the pharmacies or clinics first to identify the availability of the product. Thus, with this system, community can check early the availability of the product at the certain pharmacies or clinics without going to that places via updated drugs information in the system. Users may also order it online. This system ease user to find the location based on users' demand on the drugs needed and the system will suggest the nearest location of the pharmacies or clinics that have the criteria of user finding. This research is significant towards health and care development in society using that aligned with IR4.0 technology online and cloud system.

\section{ACKNOWLEDGEMENT}

The authors would like to thank the Research Management Centre (RMC), Universiti Teknologi MARA, Shah Alam for the support grant in publishing this paper.

\section{REFERENCES}

[1] Nath B, Reynolds F, Want R. RFID Technology and Applications. IEEE Pervasive Computing. 2006;5:22-4.

[2] Camacho-Cogollo JE, Bonet I, Iadanza E. RFID technology in health care. Clinical Engineering Handbook: Elsevier; 2020. p. 33-41.

[3] Abdulkadhim FG, Yi Z, Khalid M. SMART PHARMACY MONITORING SYSTEM BASED ON MQTT PROTOCOL USING RFID AND RASPBERRY PI. EUREKA: Physics and Engineering. 2020:98-104.

[4] Khan S, Asim M, Manzoor S. Impact of Information Technology on Internal Supply Chain Management Implementation of RFID Tags. European Journal of Business and Management Research. 2020;5.

[5] Balog M, Iakovets A, Husar J. RFID Monitoring and Accounting System in Health-Care Facilities. 4th EAI
International Conference on Management of Manufacturing Systems: Springer; 2020. p. 19-31.

[6] Hui TK, Mohammed B, Donyai P, McCrindle R, Sherratt RS. Enhancing Pharmaceutical Packaging through a Technology Ecosystem to Facilitate the Reuse of Medicines and Reduce Medicinal Waste. Pharmacy. 2020;8:58. https://doi.org/10.3390/pharmacy8020058

[7] Yusof EMM, Azmi MI, Othman MS, Mohd Yusof AR. RFID tag-based dashboard for factory production line improvement. International Journal of Advanced Trends in Computer Science and Engineering. 2020;9:155-7.

[8] Youssef W, Zaid AO, Mourali MS, Kammoun MH. RFIDbased System for Secure Logistic Management of Implantable Medical Devices in Tunisian Health Centres. 2019 IEEE International Smart Cities Conference (ISC2)2019. p. 83-6.

[9] Chamekh M, Asmi SE, Hamdi M, Kim T. Context aware middleware for RFID based pharmaceutical supply chain. 2017 13th International Wireless Communications and Mobile Computing Conference (IWCMC)2017. p. 191520.

[10] Yousif A, Peláez S, Lemière C, Forget A, Dalal C, Turcotte M-K, et al. Development of a Web-Based Tool Built From Pharmacy Claims Data to Assess Adherence to Respiratory Medications in Primary Care. Respiratory Care. 2020.

[11] Noor A, Assiri A, Ayvaz S, Clark C, Dumontier M. Drugdrug interaction discovery and demystification using Semantic Web technologies. Journal of the American Medical Informatics Association. 2017;24:556-64. https://doi.org/10.30534/ijeter/2020/41872020

[12] Delgado A, Huamaní EL, Diego SS. Design of web systems for inventory control in the e-commerce sector under the agile methodologies approach. International Journal of Emerging Trends in Engineering Research. 2020;8:3129-33.

[13] Samuel, Girsang AS. Implementation of service oriented architecture using web API \& SOMA in e-commerce web application. International Journal of Emerging Trends in Engineering Research. 2020;8:3410-9.

[14] Hahnel D, Burgard W, Fox D, Fishkin K, Philipose M. Mapping and localization with RFID technology. Robotics and Automation, 2004 Proceedings ICRA '04 2004 IEEE International Conference on2004. p. 1015-20 Vol.1.

[15] Luo W, Chen S, Li T, Chen S. Efficient missing tag detection in RFID systems. 2011 Proceedings IEEE INFOCOM2011. p. 356-60.

[16] Rashid SM, McCusker JP, Pinheiro P, Bax MP, Santos H, Stingone JA, et al. The Semantic Data Dictionary-An Approach for Describing and Annotating Data. Data Intelligence. 2020:443-86.

[17] Kassim M, Mazlan H, Zaini N, Salleh MK. Web-based student attendance system using RFID technology. Proceedings - 2012 IEEE Control and System Graduate Research Colloquium, ICSGRC 20122012. p. 213-8.

[18] Zainal Arifin MA, Kassim M, Mahmud AR, Izwan Suliman S. Automation security system with laser lights 
Murizah Kassim et al., International Journal of Emerging Trends in Engineering Research, 8(8), August 2020, 4625 - 4631

alarm on web pages and mobile apps. ISCAIE 2019 2019 IEEE Symposium on Computer Applications and Industrial Electronics2019. p. 287-92.

[19] Bahri S, Zoghlami N, Abed M, Tavares JMRS. BIG DATA for Healthcare: A Survey. IEEE Access. 2019;7:7397-408.

[20] Kassim M, Said MNHM. Data analytics on interactive indoor cycling exercises with virtual reality video games. Proceedings - 2018 4th International Conference on Control, Automation and Robotics, ICCAR 20182018. p. 321-6.

https://doi.org/10.1109/ICCAR.2018.8384693

[21] Manoochehri HE, Kadiyala SS, Nourani M. Predicting Drug-Target Interactions Using Weisfeiler-Lehman Neural Network. 2019 IEEE EMBS International Conference on Biomedical \& Health Informatics (BHI)2019. p. 1-4. 